\title{
Más publicaciones alemanas sobre la guerra de la Independencia. Las «memorias» de Karl Franz v. Holzing de 1937: una novela de ideología nazi
}

\author{
HILTRUd Friederich-StegmanN
}

\begin{abstract}
More German publications about the Spanish Napoleonic War. Karl Franz v. Holzing's «memoires» of 1937: a novel of Nazi ideology
\end{abstract}

\begin{abstract}
RESUMEN
En este artículo queremos demostrar que el oficial Karl Franz v. Holzing no es el autor de sus presuntas memorias, publicadas en 1937, que cuentan su participación en la guerra de la Independencia española. Vamos a ofrecer varias pruebas que identifican el libro como una novela, escrita por Max Emil Dufner-Greif, cuyo objetivo principal era la idealización del soldado alemán y la glorificación de la guerra. Además, añadimos como anexo una tercera bibliografía, con la cual ampliamos las anteriores, publicadas en 2003 y 2008.
\end{abstract}

PALABRAS CLAVE: Guerra de la Independencia / publicaciones alemanas / tropas de Baden / K.F. v. Holzing / memorias / M.E. DufnerGreif / novela histórica

\begin{abstract}
In this article we would like to show that the officer Karl Franz v. Holzing is not the author of his supposed memoires, published in 1937, which inform about his participation in the Spanish Napoleonic War. We shall offer some examples which will prove the book to be a novel, written by Max Emil Dufner-Greif, whose main objective was the idealization of the German soldier and the glorification of war. Furthermore, we shall include in the appendix a third bibliography, which is an extension of the two published in 2003 and 2008.
\end{abstract}

KEYWORDS:

Spanish Napoleonic War / German publications / troops of Baden / K.F. v. Holzing / memoirs / M.E. Dufner-Greif / historical novel 
Ich kam nun in der Mancha reiche Fluren, Ach, unauslöschbar sind des Krieges Spuren, Und die Zerstörung schauderhaft. (Karl Franz v. Holzing)

Llegué a los ricos campos de La Mancha. $¡$ ¡Ay! Imborrables son las huellas de la guerra Y horrorosa es la destrucción.

(Karl Franz v. Holzing)

Con motivo de nuestra participación en los preparativos de la exposición del Parque Nacional de Cabrera, titulada Oblidats a Cabrera. El captiveri napoleònic $1809-1814^{2}$, hemos vuelto al tema de las memorias alemanas sobre la guerra de la Independencia española. Hemos encontrado más publicaciones al respecto, como se puede ver en la bibliografía que añadimos como anexo ${ }^{3}$, y con la que ampliamos las anteriores, publicadas en $2003^{4}$ y $2008^{5}$.

Las memorias del joven oficial Karl Franz von Holzing (1787-1839) de Ettlingen, en Baden, llamaron nuestra atención y nos van a ocupar en este artículo. El autor, cuyo grafito todavía se encuentra en el castillo de Bellver, en Palma de Mallorca ${ }^{6}$, donde fue preso junto con más oficiales alemanes, la mayoría de ellos de la brigada Schwarz ${ }^{7}$, formó parte de un contingente de Baden ${ }^{8}$, que consistió en un regimiento de infantería y una batería, y que luchó en las tropas de la Deutsche Division [División Alemana], (a partir del 29 de julio de 1809, por orden de Napoleón, llamada Rheinische Bundesdivision [División de la Confederación del Rin]), según nos cuenta en sus memorias publicadas en 1824 en Freiburg bajo el título Meine Gefangennehmung in Spanien, vierjährige Gefangenschaft in Alicante, auf den

1 Holzing, Karl Franz v.: Meine Gefangennehmung in Spanien [...]. Freiburg (Franz Xaver Wangler) 1824, p. 101.

2 Friederich-Stegmann, Hiltrud: «Cabrera en las memorias de los prisioneros alemanes.» En: Amengual, Pep y otros: Oblidats a Cabrera. El captiveri napoleònic 1809-1814. Eds.: Parc Nacional de Cabrera y Conselleria de Medi Ambient, Govern Balear. Palma de Mallorca (Promomallorca Edicions S.L.) 2009. (Catálogo de la exposición en CaixaForum, Palma de Mallorca, 28.10.2009 — 17.01.2010), pp. 170-193.

3 Véase: Anexo 2.

4 Friederich-Stegmann, Hiltrud: «Memorias de alemanes en España durante la Guerra de la Independencia. La estancia de Philipp Schwein en la isla de Cabrera». En: Espacio, Tiempo y Forma, Serie IV, H. ${ }^{\text {a }}$ Moderna, t.16, 2003, pp. 359-390.

5 Friederich-Stegmann, Hiltrud: «Más textos de alemanes sobre la guerra de la Independencia. El Dos de Mayo de Madrid y el primer sitio de Zaragoza en las memorias de Johann Konrad Friederich, llamado "el Casanova alemán"». En: Espacio, Tiempo y Forma, Serie IV, Historia Moderna, t. 21, 2008, pp. 167207.

6 Véase: González Gonzalo, Elvira: «Après Baylen. Los grafitos de los oficiales franceses en el castillo de Bellver y algunos más de Cabrera.» En: Amengual, Pep y otros: Oblidats a Cabrera. El capitveri napoleònic 1809-1814. [...]. Op. cit., pp. 267-287; imagen del grafito en p. 272. La autora se refiere a menudo a las memorias de Karl Franz v. Holzing en la edición de 1825, según se citan en francés en Geisendorf-Des Gouttes, Théophile: Les prisonniers de guerre sous le Premier Empire. l: Geôles et pontons d'Espagne. L'expedition et la captivité d'Andalousie. II: Les Archipels enchanteurs et farouches (Baléares et Canarias. Cabrera, l'île tragique). Ginebra (Labor) 1932-1937.

7 Para más detalles, véase: nota 2.

8 Sobre las tropas de Baden en España, véase: Anexo 1. 
Más publicaciones alemanas sobre la guerra de la Independencia. Las «memorias»...

balearischen Inseln, und endlich, nach erlangter Freiheit, die Rückreise über Genua durch die italienische und teutsche Schweiz in's Vaterland, nebst Gedichten und Charaden [Mi captura en España, mis cuatro años de cautiverio en Alicante, las Islas Baleares, y finalmente, tras mi liberación, mi vuelta a la patria, pasando por Génova y la Suiza italiana y alemana. Con poemas y charadas] $]^{9}$. En 1825 se publicó una segunda edición de este libro, con el mismo título y contenido.

El título de las memorias de v. Holzing señala ya que el libro está dividido en dos partes. La primera, que tiene 88 páginas, está dedicada principalmente al tiempo más duro de la estancia del autor en España, su apresamiento, su estancia en diferentes hospitales y los cuatro años de su cautiverio en Alicante y las Baleares, sobre todo en Íbiza. Está escrita en primera persona y, exceptuando los cinco textos poéticos incluidos, titulados... Klage... [... ayes...], su tono es objetivo y su estilo más bien seco. Aunque tampoco faltan algunas informaciones topográficas, históricas y sociales sobre España, no son tan detalladas e interesantes como las de otras memorias destacadas como, por ejemplo, las del teniente Johann Konrad Friederich de Frankfurt ${ }^{10} \mathrm{o}$ las de Franz Xaver Rigel, otro oficial de Baden ${ }^{11}$. La segunda parte del libro de v. Holzing tiene 135 páginas y ofrece una colección de poemas y charadas, algunas escritas durante el cautiverio del autor. En ellas sorprende que sólo raras veces se encuentre alguna referencia a España.

Bajo el nombre de Karl Franz von Holzing se publicó en 1937, en Berlín, el libro Unter Napoleon in Spanien. Denkwürdigkeiten eines badischen Rheinbundoffiziers (1787-1839). Aus alten Papieren herausgegeben von Max Dufner-Greif [Bajo Napoleón en España. Memorias de un oficial de Baden (1787-1839) en la Confederación del Rin. Editado a partir de antiguos documentos por Max Dufner-Greif] ${ }^{12}$ El título quiere hacernos creer que se trata de las memorias de Karl Franz v. Holzing, en relación con toda su estancia en España, editadas por Max Dufner-Greif. Este libro está escrito también en primera persona y dividido en los siguientes quince capítulos: I Ausmarsch [Salida] — II Abenteuer in Bayonne [Aventura en Bayona] - III Feuertaufe bei Zornoza [Bautismo de fuego cerca de Zornoza] - IV Krankenlager in Santander [Enfermo en Santander] — V Wiedersehen in Madrid

${ }^{9}$ Esta primera edición se cita en: Merkle, Hans: «Vor zweihundert Jahren: Badische Soldaten in Spanien (1808-1814).» En: Badische Heimat, n.을, junio 2008, pp. 263-279.

10 Véase: nota 5.

${ }^{11}$ Rigel, Franz Xaver: Der Siebenjährige Kampf auf der Pyrenäischen Halbinsel vom Jahr 1807 bis 1814, besonders meine eigenen Erfahrungen in diesem Kriege nebst Bemerkungen über das Spanische Volk und Land. 3 tomos. Rastatt 1819 y 1822. Rigel, Franz Xaver: Erinnerungen aus Spanien. Aus den Papieren des Verfassers des Siebenjährigen Kampfes auf der Pyrenäischen Halbinsel von 1807 bis 1814. Mannheim (Schwan und Götz) 1839. Estos libros se encuentran en la Biblioteca alemana Görres de Madrid. Más publicaciones del autor en: Friederich-Stegmann (2003), op. cit., p. 388. Véase: nota 4.

12 Este libro se encuentra tanto en la Biblioteca alemana Görres como en la Biblioteca Nacional de Madrid.

Hay una nueva edición: Holzing, Karl Franz von \& Ludwig von Grolmann: Zwei Badener in Spanien die Memoiren von Karl Franz von Holzing und Ludwig von Grolmann. Güthersloh (Peter Schuchhardt's Compagnie d'Elite) 2000. No hemos conseguido ver este libro. Según nos informa Anne Dollhopf de Nuremberg se trata sólo de fotocopias encuadernadas, en el caso de v. Holzing del texto de 1937. Damos las gracias a Anne Dollhopf por su información. 
[Reencuentro en Madrid] — VI Rückkehr zum Regiment [Regreso al regimiento] — VII Strafzug nach Arenas [Expedición represiva a Arenas] - VIII Meza de Ibor IX Medellín - X Talavera - XI Almonacid und Ocaña [Almonacid y Ocaña] - XII Schuld und Sühne [Culpa y reconciliación] - XIII In den Hospitälern von Alicante [En los hospitales de Alicante] - XIV Von Insel zu Insel [De isla en isla] - XV Von Ibiza in die Heimat [Desde Íbiza a la patria].

Estos títulos nos indican que los once primeros capítulos del libro de 1937 se centran principalmente en el destino de las tropas de Baden en España durante los tres primeros años de la guerra y en su participación en algunas de las grandes batallas de $1809^{13}$. A partir de la mitad del capítulo doce, en concreto de la página 208 en adelante, se cuenta la captura, el cautiverio y el regreso a casa de v. Holzing. No cabe duda de que esta parte del libro de 1937 se basa en el texto de v. Holzing de 1824. No obstante, al comparar estas últimas 78 páginas con las de las memorias de 1824, llaman la atención, aparte de diferencias formales, el estilo diferente y la narración de algunos episodios adicionales. Además en el libro de 1937 faltan la segunda parte del texto original, dedicada a poemas y charadas, y también los cinco textos poéticos incluidos en la primera parte del texto original de 1824 (pp. 45-57). Se titulan: Erste Klage. Gefangenschaft [Primeros ayes. Cautiverio] Zweite Klage. Freundschaft [Segundos ayes. Amistad] — Dritte Klage. Einsamkeit [Terceros ayes. Soledad] — Vierte Klage. Genuss [Cuartos ayes. Disfrute] — Fünfte Klage. Mitgefühl [Quintos ayes. Compasión].

Para ilustrar la diferencia en la manera de narrar de v. Holzing y de DufnerGreif hemos elegido y traducido el episodio donde el capturado y herido v. Holzing describe al guerrillero Franciquete ${ }^{14}$ :

Versión de v. Holzing, 1824:

Cada vez que pasamos por un pueblo tocaban las campanas; - los hombres tiraban sus sombreros al aire; las muchachas bailaban tocando las castañuelas; las mujeres nos tiraban piedras, y por todas partes se oía el grito: ¡Viva Franciquete! Era el jefe de la guerrilla. Estaba «condecorado» con la cruz de los oficiales de la Legión de Honor francesa, la cruz de la Corona de Hierro y la orden del Mérito Militar de Westfalia, tratándose de condecoraciones quitadas a oficiales capturados. Llevaba una corta chaquetita azul con vuelta roja, pantalones amarillos y botas duras; una ancha y larga espada de dragones estaba fijamente ceñida a su lado, y un sombrero redondo embellecía su imagen ${ }^{15}$.

${ }_{13}$ 28.03.: Medellín; 28.07.: Talavera; 11.08.: Almonacid; 19.11.: Ocaña. Para más detalles, véase: Anexo 1.

${ }^{14}$ Sobre el guerrillero Francisquete, véase el siguiente artículo: Ruppert, Andreas: «Francisquete». En: Tranvía, n.․ 33, junio de 1994, pp. 42-44. Ruppert utiliza la edición de las memorias de v. Holzing de 1825.

15 Versión alemana de 1824: «So oft wir durch ein Dorf kamen, wurde mit den Glocken geläutet; die Männer warfen die Hüte in die Höhe; die Mädchen tanzten, mit den Castañettas spielend; die Weiber warfen uns mit Steinen, und überall tönte der Ruf: Viva Francisquete! Dieser war der Anführer der Guerilla. Er war mit dem Officier-Kreuze der französischen Ehren=Legion, dem Kreuze der eisernen Krone, 


\section{Versión de Dufner-Greif, 1937:}

Cada vez que pasamos por un pueblo tocaban las campanas, y la gente inundaba las calles con el júbilo del deseo de libertad. Gritando los hombres tiraban sus sombreros redondos al aire, las muchachas tocando las castañuelas bailaban alrededor de mi infeliz carro de sangre y las mujeres nos tiraban piedras y fruta podrida. Una patriota especialmente fogosa se dejó ver en sus ventanas con sus faldas levantadas, mostrándome su culo desnudo, y la gente se reía a carcajadas.

Así, los cautivos sufrían el desprecio general mientras que a los guerrilleros se les recibía con todos los honores posibles. A menudo los curas salían de las iglesias para recibirlos y bendecirlos con el Santísimo. Por todas partes se oía con estrépito: «iViva Francisquete!»

Este cabalgaba con orgullo en frente de nuestra cadena. Montaba un caballo negro ensillado de manera mora totalmente en rojo encarnado, y alegremente lo dejó hacer escarceos. También su ropa era más que llamativa. Llevaba una corta chaquetita azul, decorada de vueltas rojas y cordones del mismo color, junto con pantalones amarillos y botas duras con espuelas estrelladas de plata. Una ancha y larga espada de dragones estaba fijamente ceñida a su lado, por la cintura llevaba una faja roja y amarilla con flecos dorados, y su negro sombrero campesino estaba decorado con una cinta roja con el lema real. El orgulloso español había decorado su pecho con la cruz de los oficiales de la Legión de Honor francesa, la cruz de la Corona de Hierro y la orden del Mérito Militar de Westfalia. Estas condecoraciones se las había quitado a las víctimas presas ${ }^{16}$.

und dem Westfälischen Militär=Verdienst=Orden geschmückt, welche Ehrenzeichen er gefangenen Officiren abgenommen hatte; - er trug ein kurzes Jäckchen, mit rothem Aufschlage, gelbe Hosen und Steifstiefel; ein breiter, langer Dragoner-Degen war fest an seine Seite geschnallt, und ein runder Hut verschönerte seinen Aufzug.» (p. 7). La captura de v. Holzing está descrita en las páginas 5 y 6 (edición de 1824) que también han servido de fuente a Sauzey [Jean-Camille-Abel-Fleuri]: Les Allemands sous les Aigles Françaises: Essai sur les Troupes de la Confederation du Rhin, 1806-1814. Tomo 2: Le Contingent Badois. Avec un Préface de M.J. Margerand. París 1904. En la página 128 leemos: «Le 15 mai, près Consuégra, le lieutenant Heres avec 50 voltigeurs tombe dans une embuscade et périt avec tout son détachement; quatre jours après, 114 hommes, comandes par le lieutenant von Holzing et venant de Mora pour chercher des vivres, sont ataques pendant la nuit par des guérillas: après une résistance énergique et une infructueuse tentative pour s'ouvrir un chemin à la baïonnette, toute cette troupe est tuée ou prise par l'ennemi.»

16 Versión alemana de 1937: «So oft wir durch ein Dorf kamen, wurde mit den Glocken geläutet, und das Volk flutete im Jubel seiner Freiheitslust durch die Gassen. Die Männer warfen wiehernd die runden Hüte in die Höhe, die Mädchen tanzten, mit den klappernden Castañettas spielend, um meinen unglücklichen Blutkarren, und die Weiber warfen mit Steinen und faulen Früchten. Eine ganz besonders feurige Patriotin hob sogar in ihren Fenstern die Röcke und zeigte mir unter dem Gelächter des Volks den blanken Hintern.

Während uns Gefangene so die allgemeine Verachtung traf, wurden die Guerilleros mit allen erdenklichen Ehren empfangen, oft kamen ihnen die Geistlichen aus den Kirchen entgegen, um sie mit dem Allerheiligsten zu segnen. Überall ertönte brausend der Ruf: „Viva Francisquete! «

Dieser ritt stolz an der Spitze unseres Zugs auf einem in maurischer Art ganz blutrot gesattelten Rappen, den er übermütig tanzen liess, und auch seine Bekleidung war auffällig genug. Er trug ein kurzes blaues Jäckchen, das mit roten Aufschlägen und verschlungenen Litzen von gleicher Farbe geschmückt war, dazu gelbe Hosen und Steifstiefel mit silbernen Sternsporen. Ein breiter langer Dragonerdegen war fest an seine Seite geschnallt, um die Hüfte trug er eine rotgelbe Schärpe mit Goldfransen, und der schwarze Bauernhut war mit einem roten Königsdevisenband umwunden. Seine Brust hatte der stolze Spanier mit dem Offizierskreuz der französischen Ehrenlegion, mit dem Kreuze der eisernen Krone und dem westphälischen Militärverdienstorden geschmückt. Er hatte diese Ehrenzeichen gefangenen Opfern abgenommen.» (p. 217). 
Este ejemplo demuestra claramente que el autor Dufner-Greif utilizó el texto de v. Holzing de 1824 (o su reedición de 1825), pero que cuenta el episodio de una manera más novelesca.

Respecto a las primeras 207 páginas de la publicación de 1937 estamos convencidos de que Dufner-Greif tampoco editó viejos manuscritos de v. Holzing, como quiere hacernos creer en el subtítulo del libro, que anuncia la edición de «antiguos documentos». Según nuestra opinión puede haber utilizado sobre todo las memorias y diarios de otros oficiales de Baden ${ }^{17}$. Por ejemplo, hay grandes semejanzas en la descripción de algunas batallas y saqueos con el modo de narrar dichas acciones por Franz Xaver Rigel en sus memorias. Para demostrarlo hemos elegido y traducido el episodio del saqueo de Arenas $^{18}$ :

\section{Versión de Rigel:}

Los horrores del saqueo y de la terrible destrucción por parte de los granaderos y dragones se multiplicaron después del regreso de los regimientos que habían perseguido al enemigo. Con el mismo fin y por expresa orden del jefe de la división se les llevaba por turnos a la ciudad. [...] La inmensa cantidad de vino almacenado encontrada aquí hubiera sido suficiente durante tres meses para todo nuestro cuerpo si se hubiera distribuido adecuadamente. Uno se puede imaginar fácilmente la fatal reacción que causó tal abundancia en una multitud de hombres que forzosamente habían tenido que guardar un estricto régimen desde hacía ya cuatro semanas. Además faltó poco para que, incluso entre los compañeros de la división alemana, se hubieran producido sangrientas peleas, porque, algunas horas después de la conquista de la ciudad, tres tercios de ellos culebreaban borrachos por las calles y las casas. Los dragones tampoco estaban en mejor estado. Además llamó la atención la manera de manifestarse estos abusos: Por aquí se veía a un holandés con quesos en una mano y una enorme jarra de vino en la otra. Su uniforme blanco estaba enrollado por hojas empapadas de tabaco recién tratado. Por allí había un francés acoplado de la misma manera y además cargado con un montón de trajes españoles de mujeres. Por aquí se veía a un alemán con embutidos y jamones colgando alrededor de todo su cuerpo, [...]. Otros, borrachos y cantando con voz ronca, pasaban por las calles detrás de un músico tambaleándose, que no conseguía producir tonos armónicos con una guitarra robada. Otros, ataviados con hábitos de monjes y cofias viejas, bailaban al son de un violín que sólo tenía la mitad de sus cuerdas. Otros maldecían, muchos discutían sin saber por qué, o habían ocupado los balcones actuando como predicadores absurdos y bufones $[\ldots]^{19}$.

17 Véase las bibliografías en nuestros mencionados artículos, publicados en 2003 y 2008.

18 En Sauzey, tomo 2, op. cit., p. 109, no se habla de la participación de los franceses en el saqueo de Arenas: «[...] les Allemands rentrent à Talavère après avoir pillé et brûlé la petite ville d'Arenas, en représaille du massacre que les habitants y avaient fait le 25 février de tout un détachement composé de 25 chevau-légers westphaliens. «

19 Versión alemana de Rigel: «Der Plünderung und wilden Verwüstung Greuel, denen die Grenadiere und Dragoner sich überlassen, mehrten ihre Schrecken nach Rückkehr der Regimenter, welche den Feind verfolgt. Sie wurden auf ausdrücklichen Divisionsbefehl zu gleichem Zwecke ablösungsweise in die Stadt geführt. [...] Die ungeheuren Weinvorräthe, die man hier fand, würden bei gehöriger Vertheilung ein Vierteljahr lang für unser ganzes Armeecorps hingereicht haben. Wie wenig vortheilhafte Wirkungen ein solches Übermass auf den grossen Haufen äussern musste, der seit vier Wochen auf eine gezwungene 


\section{Versión de Dufner-Greif:}

Durante la persecución del enemigo, más allá de Arenas, sólo los dragones y grenaderos habían recibido la orden de quedarse en la ciudad con el fin de proteger a los altos cargos, pero, después del regreso de los demás, el jefe de la división mandó llevar a los regimientos por turnos a la ciudad con el fin de saquear.

La imagen en las calles era increíble. Había camas y vestidos dispersos de manera caótica, pues los saqueadores habían tirado a la calle todos los enseres de las casas y todos estos trastos estaban cubiertos de pedazos de vidrio de espejos y ventanas rotas. En las bodegas encontraron inmensas cantidades de vino almacenado, y, como los hombres no habían probado bebidas alcohólicas durante mucho tiempo, se arrojaron sobre las jarras de barro y se emborracharon hasta el desmayo.

La pequeña ciudad parecía un manicomio. La manera de saquear ya le decía mucho al callado observador: Por aquí corrían holandeses con queso y tabaco, por allí alemanes cargados de embutido y jamón, y entre ellos andaban en zig zag los franceses con objetos robados de las iglesias y artículos femeninos. En la plaza del mercado había una verdadera vida carnavalesca: Por aquí unos se habían puesto hábitos de monjes, y otros ropa interior de mujeres, por allí toda una banda se había aprovisionado de instrumentos y producía un terrible ruido infernal, en el balcón de una casa un borracho pronunciaba un discurso carnavalesco mientras que, en frente, otro se había puesto el ornato de un cura y gritaba „salterios” de contenido sacrílegos a la multitud. P. $94^{20}$.

\footnotetext{
Diät angewiesen war, lässt sich leicht entnehmen. Auch fehlte nicht viel, dass es selbst unter den Waffengenossen der Teutschen Division zu blutigen Auftritten gekommen wäre, da drei Viertheil derselben einige Stunden nach der Eroberung betrunken in den Strassen und Häusern herumtaumelten. Die Dragoner befanden sich in keinem bessern Zustande. Ausserdem verriehten sich die Folgen dieser Unmässigkeit noch auf die auffallendste Weise. Hier sah man einen Holländer mit Käsen in der Hand, mit einem mächtigen Weinkruge in der andern, seine weisse Uniform mit Rollen frisch gebeitzten triefenden Rauchtabaks umwunden, dort einen Franzosen, auf ähnliche Weise ausstaffirt und überdiess mit einer Tracht Spanischer Frauenkleider beladen, hier wiederum einen Teutschen rings mit Würsten und Schinken behangen, [...]. Singend durchzogen andere mit schwerer Zunge die Strassen, ein taumelnder Leiermann voran, eben nicht harmonische Töne auf einer gestohlenen Guitarre hervorzwingend; Andere tanzten in Mönchshabiten, eine alte Weiberhaube auf dem Kopfe, nach dem Tacte einer halbbesaiteten Fiedel, Andere fluchten, Viele zankten, ohne zu wissen warum, oder standen als unsinnige Prediger und Possenreisser auf den Balcons; [...].» pp. 149, 150.

La descripción de escenas pintorescas en la obra de Rigel se parece mucho al estilo del libro de viaje de Christian August Fischer, del cual Rigel copió páginas enteras en la siguiente obra: Rigel, Franz Xaver: Erinnerungen aus Spanien. Aus den Papieren des Verfassers des Siebenjährigen Kampfes auf der Pyrenäischen Halbinsel von 1807 bis 1814. Mit acht Original-Abbildungen echt Spanischer Nationaltrachten. Mannheim (Schwan und Götz) 1839, pp. 202-207. Véase: Fischer, Christian August: Viaje de Ámsterdam a Génova pasando por Madrid y Cádiz en los años 1797 y 1798. Estudio preliminar, traducción, edición y notas de Hiltrud Friederich-Stegmann. Prólogo de Carlos Martínez Shaw. Alicante (Publicaciones Universidad de Alicante) 2007. (Norte Crítico, 16).

20 Versión alemana de Dufner-Greif: «Während der Verfolgung des Feindes über Arenas hinaus waren in der Stadt nur Dragoner und Grenadiere zum Schutz der höheren Stäbe belassen worden, nach unserer Rückkehr jedoch wurden wir auf ausdrücklichen Divisionsbefehl hin regimenterweise zur Plünderung in die Stadt geführt.

In den Strassen sah es toll aus, Betten und Kleider lagen wirr zerstreut, allen gewöhnlichen Hausrat hatten die Plünderer aus den Fenstern geworfen, und über alle diese Trümmer waren die Scherben von Spiegeln und Scheiben hingesät. In den Kellern waren ungeheure Weinvorräte gefunden worden. Da nun
} 
Este ejemplo nos ha servido para demostrar, que respecto a la «edición» de 1937, estamos ante una novela histórica, escrita por el pedagogo y autor Max Emil Dufner-Greif (1891-1968), parcialmente influida por las memorias de Franz Xaver Rigel. No obstante, varios historiadores (entre ellos también nosostros) ${ }^{21}$ han utilizado este libro como fuente fiable. Ludwig Vögely²2, por ejemplo, dedica un artículo exclusivamente a esta publicación de 1937 sin cuestionar su autoría ${ }^{23}$. Lo mismo ocurre con las numerosas citas de estas «memorias» en el artículo de ErnstHeinrich Schmidt sobre las tropas de Baden en España ${ }^{24}$, en el cual se habla de «la ejemplar descripción de Dufner-Greif (Holzing)» ${ }^{25}$. En la última edición, la de 2000, la autoría de estas «memorias» tampoco se pone en duda ${ }^{26}$.

El autor Max Emil Dufner-Greif era bien conocido a nivel regional27, sobre todo por sus obras de temas relativos a su patria chica, Baden ${ }^{28}$. La idealiza tanto que añade a su verdadero apellido, Dufner, el nombre del símbolo heráldico regional, Greif (grifo), para denominarse Dufner-Greif. Entre 1908 y 1911 estudió en

die Leute länger Zeit jeden Genuss geistiger Getränke hatten entbehren müssen, stürzten sie sich wild über die tönernen Krüge her und betranken sich besinnungslos.

Das Städtchen glich einem Narrenhaus. Schon das Beutemachen verriet dem stillen Beobachter viel. Da liefen Holländer mit Käse und Tabak, dort hatten sich Deutsche mit Würsten und Schinken beladen, dazwischen aber torkelten die Franzosen mit gestohlenem Kirchengut und Frauenzimmerkram. Auf dem Marktplatz herrschte ein regelrechtes Faschingstreiben, da hatten sich Kerle in ein Mönchshabit gesteckt, andere liefen im Unterzeug der Weiber herum, dort hatte sich eine ganze Bande mit Musikinstrumenten versehen und verübte einen wahren Höllenlärm, auf dem Balkon eines Hauses hielt ein betrunkener Bursche eine karnevalistische Volksrede, während inm gegenüber ein anderer in vollem Priesterornat in die Menge Psalmen gröhlte, deren Text allerdings sehr unheiliger Art war.» p. 94.

${ }^{21}$ Friederich-Stegmann (2003), op. cit., p. 370.

22 Vögely, Ludwig: «Unter Napoleon in Spanien. Denkwürdigkeiten des Hauptmanns Karl Franz von Holzing (1787-1839)». En: Badische Heimat. 69, cuaderno 1, marzo 1989, pp. 211-218. En 1957 Ludwig Vögely publicó unas páginas sobre el cautiverio de von Holzing, para las cuales se basa en la edición de 1824 o 1825. Véase: Vögely, Ludwig: "Die Erlebnisse Karl Fr. von Holzings in spanischer Gefangenschaft (1810-1814).» En: So weit der Turmberg grüsst. 9, cuaderno 2, febrero 1957, pp. 16-19.

${ }^{23}$ Según Vögely, «Holzing dejó manuscritos con sus memorias que describen sus vivencias en la guerra de España y que ahora se publicaron como libro bajo el título Unter Napoleon in Spanien. Denkwürdigkeiten eines badischen Rheinbundoffiziers.» Vögely (1989), op. cit., p. 211.

${ }_{24}$ Schmidt, Ernst-Heinrich: «Troops From Baden Fighting in the Confederation of the Rhine Forces in the Peninsula War, 1808-1809.» En: MILITARIA. Revista de Cultura Militar, n. - 7. Servicio de Publicaciones, UCM, Madrid, 1995, pp. 360-389. Schmidt no muestra ninguna duda acerca de esta publicación de 1937 y en sus notas la cita muy a menudo como una fuente fiable.

${ }_{25}$ Schmidt, op. cit., p. 382, nota 69.

26 Véase: nota 12.

27 Por ejemplo, se publicó el siguiente artículo sobre su obra: Straub, Karl Willy: «Max Dufner-Greif, ein deutscher Dichter am Oberrhein.» En: Die Wacht im Westen, 4, 1936/37.

28 Una lista de sus publicaciones en: Ferdinand, Horst: DUFNER-GREIF, Max Emil, Pädagoge, Schriftsteller. S.I., s.a. [Manuscrito]. Esta corta biografía de tres páginas a máquina, junto con más documentos sobre Max Dufner-Greif, se conserva en el Archiv Manfred Bosch, que se encuentra en el Franz-Michael-Felder-Archiv der Vorarlberger Landesbibliothek/Vorarlberger Literaturarchiv, bajo la signatura: Zahl lib-VLB 55.004/Bosch. Damos las gracias al director de este archivo, Dr. Jürgen Thaler, por habernos enviado las copias de dicho material y por la autorización de utilizarlo en este artículo. Véase también: Ferdinand, Horst: «Dufner-Greif, Max Emil, Pädagoge, Schriftsteller». En: Badische Biographien. Tomo 2 [Hasta ahora 4 tomos]. Stuttagrt (Kohlhammer) 1994, pp. 93-95. El texto es una versión algo más amplia del manuscrito arriba mencionado. Empieza con una detallada cronología de la vida de DufnerGreif, sobre todo la profesional, hasta su jubilación en 1949. Damos las gracias por las copias a Renate Lichtenwald-Rast de la Badische Landesbibliothek Karlsruhe. 
la Escuela de Magisterio de Freiburg, y de 1911 a 1914 trabajó de maestro, profesión que ejerció también después de la primera guerra mundial. Como muchos hombres de su generación, participó en las dos guerras mundiales. De la primera regresó con el grado de teniente de reserva y la condecoración de la Cruz de Hierro EK I y EK II, la Cruz de Caballero del León de Zähringen y la Medalla de Heridos, por haber sufrido varias intoxicaciones de gas. De la segunda regresó ya en 1943 debido a una grave enfermedad. Hasta su final fue director en diferentes escuelas y después pasó aproximadamente un año en un lager francés. A continuación vivió tres años en la miseria hasta ser reconocido como menos culpable y jubilado en 1949 con la pensión de un maestro. Él mismo indicó tres pilares de su vida: lo poético, lo militar y lo político ${ }^{29}$. Sus artículos se publicaron, por ejemplo, en el Führer, la revista de la NSDAP de Karlsruhe. Por lo tanto, no es de extrañar, que, al igual que un gran número de alemanes de su época, firmara entonces sus cartas con «Heil Hitler! » ${ }^{30}$ Dufner-Greif idealiza en muchos de sus textos lo militar y la guerra, y, además, se muestra un decidido adversario de los judíos ${ }^{31}$. A veces resulta insoportable lo que escribe, por ejemplo, cuando habla de «la fe incondicional en la legitimidad del poder autoritario por la gracia de Dios.»32

La ideología nacionalsocialista se observa también en el libro que aquí nos ocupa, a pesar de tratarse de una historia de los tiempos napoleónicos. Esto no es de extrañar, ya que, según nos explica el novelista alemán Lion Feuchtwanger (1884-1958) en su ensayo Das Haus der Desdemona oder Grösse und Grenzen historischer Dichtung [La casa de Desdemona o grandeza y límites de la literatura histórica], uno de los objetivos del autor de una obra literaria de contenido histórico es transmitir lo que él considera esencial de su propio tiempo, de modo que lo histórico le sirve sólo de disfraz ${ }^{33}$.

Al tratarse de una novela, el autor puede también inventar personajes que en la historia real no existieron. Por ejemplo, pensamos que Dufner-Greif inventó la fantástica historia de amor entre la bella y rica marquesa Doña Rosa Vittoria [sic] y Karl Franz v. Holzing ${ }^{34}$. Nos quiere hacer creer que esta dama de la alta nobleza, de cuyo apellido no nos informa, pero indica que es pariente de la duquesa de Alba, siguió al joven y pobre teniente de Baden por toda España, incluso hasta Baleares. Entonces nos preguntamos por qué en sus propias publicaciones de 1824

${ }^{29}$ Véase su pequeño texto autobiográfico (con un retrato del autor), que termina con esta frase: Gott erscheint uns allein im Deutschen! (¡Diós se nos revela sólo en lo alemán!). Dufner-Greif, Max: «Max Dufner-Greif über sich selbst» [Max Dufner-Greif sobre si mismo]. En: Ekkhart-Jahrbuch, 1935, pp. 80-82.

30 Dos cartas así firmadas se conservan en el archivo arriba mencionado. Véase: nota 27.

31 Véase: nota 27, texto biográfico en manuscrito de Horst Ferdinand, op. cit., p. 2.

32 Versión alemana: «[...] unbedingten Glauben an das Gottesgnadenrecht der Gewalt im Führerstaat. 》 Cita en Horst Ferdinand en Baden-Württembergische Biographien, op. cit., p. 95.

${ }_{33}$ Feuchtwanger, Lion: Das Haus der Desdemona oder Grösse und Grenzen der historischen Dichtung. Frankfurt / Main (Fischer Tb.) 1986, p. 135.

${ }_{34}$ Dufner-Greif puede haber sacado la idea para esta historia del primer tomo de la obra de Rigel (1819), op. cit., pp. 363 y 364, donde se cuenta el episodio de la salvación de un grande y su hija. Véase: nota 11. 
y 1825 v. Holzing nunca menciona esta historia de amor, no habla de ninguna marquesa y tampoco la dedica ninguno de sus poemas ${ }^{35}$. Para demostrar lo fantástico de esta historia, citamos a continuación, a modo de ejemplo, el mismo episodio en los dos libros, es decir, cuando llevaron al gravemente herido prisionero v. Holzing al hospital de Alicante, pasando por varios pueblos. Primero citamos la versión de 1824 y después la de 1937:

Versión de v. Holzing, 1824:

Jamás olvidaré aquel momento maravilloso, cuando una muchacha española, secándose las lagrimas con el pañuelo, me tiró desde un balcón una camisa y un abrigo negro ${ }^{36}$.

\section{Versión de Dufner-Greif, 1937:}

De repente un grito ahogado dirigió mi mirada al balcón de la casa delante de la cual habíamos parado. Me quedé paralizado al reconocer a la marquesa. Se inclinó mucho sobre la barandilla de hierro y en sus ojos se veía el gran miedo que sentía al verme en un estado tan lastimoso, porque mi cuerpo desnudo estaba manchado de sangre y suciedad. Rápidamente entró en la casa. En seguida regresó y me tiró una camisa larga y un abrigo negro. Después empezó a sollozar a voces, apoyándose en la pared, mientras ocultaba la cara en su pañuelo. [...] Rígida como una estatua la mujer no paraba de llorar en su pañuelo ${ }^{37}$.

Relacionado con esta fantástica historia de amor nos llamó la atención un episodio sospechoso. El protagonista cuenta haber visto en 1809 el cuadro de Goya «Los fusilamientos del 3 de mayo», escondido bajo una cortina, en la capilla del palacio madrileño de su amada marquesa. Como esto es imposible, ya que Goya no pintó este cuadro hasta $1814^{38}$, tenemos otra prueba de lo increíble de esta historia, según nuestra opinión inventada por Max Dufner-Greif, para hacer más interesante su libro.

35 Varias poemas de v. Holzing (1824 y 1825) están dedicadas a mujeres: An Serafine, p. 110; An die zürnende Laura, p. 126; An Laura, p. 129; An Karoline, p. 134; An Adelaide, p. 135; An meine Cousine Babette, p. 135; An Louise, p. 143; An Jenny, p. 156; An Elise, p. 164; An Laura v. B., p. 183; An Chlóe, p. 186; An Laura, p. 188; An Laura, p. 189; An Caroline, p. 204; An Minna, p. 206; An die kleine Marie, p. 209; An Laura, p. 213.

${ }^{36}$ Versión alemana de v. Holzing, 1824: «Nie vergesse ich jenen herrlichen Augenblick, in welchem ein spanisches Mädchen, mit dem Tuche die Thränen trocknend, vom Balkone herab ein Hemde, und einen schwarzen Mantel mir zuwarf.» (p. 9).

37 Versión alemana de Dufner-Greif, 1937: «Ein erstickter Aufschrei lenkte plötzlich meinen Blick nach dem Balkon des Hauses, vor dem wir hielten, und mit vor Schreck gelähmten Gliedern erkannte ich die Marquesa. Sie beugte sich weit über das eiserne Geländer, in ihren Augen irrte die blasse Angst, da sie mich so elend liegen sah, denn mein nackter Leib war mit Blut und Schmutz besudelt. Auf einmal eilte sie in das Haus zurück und kam nach einigen Augenblicken wieder, sie warf mir ein langes Hemde und einen schwarzen Mantel zu, dann brach sie laut in Schluchzen aus und lehnte sich an die Wand, das Gesicht in ihrem Tuche verbergend. [...] Unaufhörlich und bewegungslos wie eine erstarrte Bildsäule weinte die Frau in ihr Tuch.» (p. 219).

38 De la edición de 2000 (véase nota 12) hay una reseña de Hendryk Loose en internet. http://222.napoleon-online.de/html/rezension_personen.html, donde también se pone en duda este episodio del cuadro de Goya, pero no la fantástica historia de amor y tampoco la autoría de v. Holzing. 
Otras partes de la novela, porque de eso se trata, no son sólo fabulosas, sino realmente chocantes. Son las que el autor utiliza para transmitir la ideología nazi, por ejemplo, cuando insulta a los judíos ${ }^{39}$, llamándoles "Schmeissmücken» (moscardas) ${ }^{40}$, y también cuando desprecia a los masones ${ }^{41}$. Sin embargo, estos no son los únicos desprecios en el libro. Hemos encontrado muchas citas ${ }^{42}$ en las cuales se insulta a los soldados franceses, llamándoles falsch, selbstsüchtig, heuchlerisch, verworfen, raubgierig, betrunken, völlig zügellos, lahm, lüstern, im Blutrausch nimmersatt, geborene Mordbrenner, die grössten Spitzbuben unter der Sonne, französische Dragonerrotte, Schandbuben, grüne Teufel, verkotzte Gesichter (falsos, egoístas, hipócritas, depravados, rapaces, borrachos, totalmente desenfrenados, débiles, lúbricos, insaciables en el delirio homicida, incendiarios natos, las peores cuadrillas de ladrones bajo el sol, la banda francesa de dragones, infames, diablos verdes, caras vomitadas). El peor papel se lo lleva siempre la Guardia de París ${ }^{43}$. Las demás naciones tampoco se libran de insultos y clichés, de forma que a los soldados ingleses les llama borrachos y a los holandeses les describe como unos comilones. A los españoles les descalifica como heuchlerisch, falsch, listig, heimtückisch (hipócritas, falsos, astutos, maliciosos). Además quiere hacernos ver que los españoles, salvo en algunas ocasiones excepcionales, eran en su mayoría soldados malos y cobardes, que casi siempre estaban huyendo ${ }^{44}$. Por ejemplo leemos:

Los españoles [...] no apuntan con cuidado y simplemente disparan al azar [... $]^{45}$.

Los alborotados españoles [...] disparaban sin fijarse bien y con la mano temblando $[\ldots]^{46}$.

39 Dufner-Greif (1937), pp. 27, 38, 39.

40 Sobre el antisemitismo alemán ya en las primeras décadas del siglo XIX, y también sobre otras terribles denominaciones parecidas, véase: Herzig, Arno: «Brandstifter im Biedermeier. Wie man in Minden und andernorts den Hass auf die Juden schürte - und die Epoche zur Ursprungszeit des modernen Antisemitismus in Deutschland wurde.» En: DIE ZEIT, n. 4, 2010, p. 78. Respecto a la terminología nacionalsocialista queremos recomendar este excelente diccionario de 710 páginas: Schmitz-Berning, Cornelia: Das Vokabular des Nationalsozialismus. (De Gruyter) 1998.

El desprecio hacia los judíos también se encuentra en la obra de Rigel, op. cit., tomo 1, p. 38.

${ }^{41}$ Dufner-Greif (1937), pp. 27, 38, 39, 53, 193. 207.

${ }^{42}$ Dufner-Greif (1937), pp. 38, 42, 44, 45, 49, 63, 89, 95-99, 120, 122, 131, 134, 145, 148, 161, 193 ,

${ }^{43}$ También en la obra de Rigel se observa este juicio, por ejemplo, en el tomo 1 (1819), pp. 399 y 411. Sobre la Guardia Imperial de Napoleón, véase, por ejemplo: Haythornthwaite, Philip y Bryan Fosten: Die Kaiserliche Garde Napoleons. Berlín (Siegler) 2008.

${ }_{44}$ De nuevo observamos una influencia de Rigel, que dice de los soldados españoles: «[...] hay noticias que describen a los españoles como unos soldados excelentes y valientes. Por lo general esta no era mi impresión. Cuando aparecíamos en campo abierto, huían si no eran por lo menos cuatro veces más que nosotros. Sólo en la guerrilla o en combates de montaña y detrás de unos fuertes muros mostraban más valentía.» Rigel, op. cit., tomo 1, prólogo, p. XXXIX).

45 «Die Spanier [...] zielen nicht besonnen und pulvern einfach in den Tag hinein [...].» (p. 108).

46 «Die Spanier schossen in ihrer Unruhe [...] ohne sicheres Auge und ohne feste Hand [...].» (pp. $114,115)$. 

$[\ldots] \cdot{ }^{47}$

A pesar de los esfuerzos de los comandantes españoles, los milicianos huían

A la una de la madrugada los españoles [...] empezaron un furioso tiroteo. Probablemente combatían con fantasmas ${ }^{48}$.

Derrotamos a los españoles, que se retiraron $[\ldots]^{49}$.

Los españoles huyeron rápidamente de su avanzado puesto y se retiraron al punto más alto de su primera posición ${ }^{50}$.

[...] los sorprendidos españoles huyeron en una fuga desbaratada, sin que nuestra infantería tuviera que mover un dedo. [...] El resto huyó en un desorden desencadenado ${ }^{51}$.

[...] los enemigos [los españoles] huyeron muy deprisa ${ }^{52}$.

$[\ldots]$ los enemigos huyeron con todos los signos del horror $[\ldots]^{53}$.

$[\ldots]$ los españoles se dieron rápidamente a la fuga $[\ldots]^{54}$.

[...] los enemigos emprendieron la fuga tras una corta defensa ${ }^{55}$.

$[\ldots]$ los dispersos restos huyeron $[\ldots]^{56}$.

En este retablo de blanco y negro ${ }^{57}$, no nos sorprende que respecto a los soldados alemanes sólo se puedan leer elogios. Los adjetivos más usados son gesellig, gutmütig, brav, menschlich, edelmütig, einfach, tapfer, kameradschaftlich, fröhlich, wacker, trefflich, tatkräftig, gemütlich, ruhig, gewitzt, kaltblütig, treu (sociables, bonachones, obedientes, humanos, nobles, sencillos, valientes, amigables,

\footnotetext{
47 «Trotz aller Bemühungen der spanischen Führer liefen die Milizbauern davon [...].» p. 115.

48 «Um ein Uhr in der Nacht huben die Spanier [...] eine tolle Schiesserei an, wahrscheinlich haben sie mit Gespenstern gekämpft.» (p. 151).

49 «Wir jagten die weichenden Spanier vor uns her [...].» (p. 161).

50 «Die Spanier verliessen ihren vorgeschobenen Posten in wilder Flucht und zogen sich auf den höchsten Rand der ersten Stellung zurück.» (pp. 163 y 164).

51 «...] in wilder Flucht brausten die verdutzten Spanier davon, ohne dass unsere Infantería auch nur einen Finger krumm gemacht hätte. [...] Der Rest jagte in entfesselter Unordnung davon.» (p. 166).

52 «...] liefen die Feinde [die Spanier] in überstürzter Flucht davon.» (p. 168).

53 «[...] die Feinde flohen mit allen Zeichen des Entsetzens [...]. (p. 186).

54 «...] die Spanier ergriffen schleunigst die Flucht [...].» (p. 187).

55 «...] da ergriffen die Feinde nach kurzer Gegenwehr die Flucht.» (p. 187).

56 «[...] die zerstreuten Reste flohen [...].» (p. 189).

57 Este maniqueo no se observa en la obra de Rigel.
} 
Más publicaciones alemanas sobre la guerra de la Independencia. Las «memorias»...

alegres, buenos, excelentes, enérgicos, joviales, tranquilos, inteligentes, impávidos, fieles). A los tan buenos alemanes se los suele contrastar, sobre todo, con los franceses, que siempre reciben el papel de malos como arriba se indica ${ }^{58}$.

El único grupo que se libra de clichés y desprecios es el de los soldados pola$\cos ^{59}$. El autor sólo tiene elogios para ellos, quizás porque, según dice, los de Baden lucharon varias veces al lado de la división polaca, por ejemplo bajo el mando del príncipe Sulkowski60, cuya valentía también elogia ${ }^{61}$.

Ya hemos visto que Max Dufner-Greif regresó condecorado de la primera guerra mundial ${ }^{62}$. Al igual que otros autores de su llamada "generación perdida" (Hemingway, Fiesta), quedó marcado por lo que vivió en el frente del oeste y en las llamadas Materialschlachten (batallas del material). Mientras que unos se convirtieron después en decididos pacifistas, como por ejemplo Erich Maria Remarque (1898-1970), cuyo libro Im Westen nichts Neues ${ }^{63}$ (Sin novedad en el frente) ${ }^{64}$ es una acusación contra la guerra y se puede considerar una de las grandes novelas antibelicistas, otros, como Ernst Jünger (1895-1998), por ejemplo en su famoso diario In Stahlgewittern ${ }^{65}$ (Tempestades de acero) ${ }^{66}$, no reflexionan sobre el sentido o la justificación de la guerra. Aunque Max Dufner-Greif no era un autor del calibre de los arriba mencionados y tampoco escribió sobre sus experiencias en la primera guerra mundial, pensamos que esta crucial experiencia de su juventud le marcó tanto que puede haber influido en la intención principal de esta novela histórica que es, en nuestra opinión, la de realizar tanto una idealización del soldado alemán como una glorificación de la guerra.

${ }^{58}$ En la siguiente obra, otra posible fuente de Dufner-Greif, también se muestra un terrible desprecio, incluso odio, hacia los franceses: [Bleibtreu, Karl]: Deutsche Waffen in Spanien. Berlín (Praeger) 1885.

Este libro está escrito en un estilo novelesco y nos parece poco fiable. Se encuentra en la Biblioteca del Senado, Madrid. Bleibtreu publicó tres libros más sobre la guerra de la Independencia española; véase nuestra bibliografía en: Friederich-Stegmann (2003).

59 Sobre la participación de soldados polacos en la guerra de Independencia española, véase, por ejemplo: Presa González, Fernando y otros: Soldados polacos en España durante la Guerra de la Independencia Española (1808-1814). Madrid (Huerga y Fierro Editores) 2004.

60 El general príncipe Antoni Pawel Sulkowski nació el 31.12.1785 en Leszno y murió el 13.04.1836 en Rydzyna. En España combatió en los años 1808 a 1810, entre otros lugares en: Toledo, Almonacid, Ocaña. Ocupó el cargo del Gobernador de la ciudad de Málaga. En 1810: general de brigada; en 1813: general de división; en octubre de 1813 (por pocos días): Comandante en Jefe del Ejército del Ducado de Varsovia. Damos las gracias por esta información a Grzegorz Bak del Departamento de Filología Eslava de la Universidad Complutense de Madrid.

61 Por ejemplo, Dufner-Greif, pp. 166, 184.

62 Sobre el entusiasmo hacia lo bélico en la literatura alemana antes y a comienzos de la primera guerra mundial, véase: Assheuer, Thomas: «Krieg veredelt den Menschen.» En: DIE ZEIT, n. 10, 4 de marzo de 2010, p. 44. Assheuer informa que hasta finales de 1915 se publicaron en Alemania 235 tomos de poesía bélica con unos 2.500 .000 poemas de temas bélicos, 800 tomos de literatura de guerra y mil sermones y predicaciones bélicas de todas las creencias.

63 Primera edición: 1929.

64 Véase, por ejemplo, esta edición española: Remarque, Erich Maria: Sin novedad en el frente. Trad.: Judith Vilar. Barcelona (Edhasa) 1994.

65 Primera edición: 1920.

${ }^{66}$ Véase, por ejemplo, esta edición española: Jünger, Ernst: Tempestades de acero. Trad.: Andrés Sánchez Pascual. Barcelona (Tusquets) 2005. 
De esta glorificación e idealización de lo bélico hay innumerables ejemplos en todo el libro. A continuación sólo queremos citar los más destacados: $[\ldots]^{67}$.

Me di cuenta de que la lucha era el verdadero sentido de la vida de un hombre

El choque con el enemigo llenó mi sangre de tanta alegría que concilié el sueño con dulce agotamiento[... $]^{68}$.

[...] por primera vez gocé el júbilo de la batalla ganada ${ }^{69}$.

Desde el campamento me dejé fascinar por el horroroso espectáculo. [Se trata del saqueo e incendio de Arenas $]^{70}$.

Este ruido de la batalla me causó una impresión embriagadora, y me acuerdo haber dado alegres gritos de júbilo por el deseo de combatir ${ }^{71}$.

Entonces vi por primera vez la caricatura del miedo a la muerte, que es la más miserable cara humana ${ }^{72}$.

El escenario [de la línea de combate] que se desarrolló delante de mí era grandioso, y me conmovió la fiebre de la grandeza ${ }^{73}$.

Nosotros, los de Baden, [...] nos lanzamos con desprecio de la muerte a las posiciones del enemigo ${ }^{74}$.

Un hombre jamás es más hermoso que cuando, con la cara roja del combate y lleno de pólvora y polvo, grita con jubilo la victoria al aire ${ }^{75}$.

En el ondeo de la bandera el eterno Dios habla a los soldados $[\ldots]^{76}$.

\footnotetext{
67 «Ich erkannte den Kampf als letzten Sinn des männlichen Lebens [...].» (p. 6).

68 «Der Zusammenstoss mit dem Feind hatte mein Blut so in einen Freudenrausch gebracht, dass ich [...] in süsser Erschöpfung einschlief, [...].» (p. 36).

69 «...] zum erstenmal kostete ich den Jubel der gewonnenen Schlacht.» (p. 37).

70 «Ich sah das schaurigschöne Schauspiel vom Lager aus.» (p. 95).

71 «Dieser Schlachtenlärm machte auf mich einen berauschenden Eindruck, ich erinnere mich, dass ich vor Kampfeslust hell gejubelt habe.» (p. 111).

72 «Da sah ich zum erstenmal die Fratze der Todesangst, sie ist von allen Menschengesichern die erbärmlichste.» (p. 115).

73 «Das vor mir aufgerollte Bild [der Schlachtlinie] war grossartig, und mich packte das Fiebre der Grösse.» (p. 150).

74 «Wir Badener [...] stürmten mit Todesverachtung auf die feindliche Stellung.» (p. 153).

75 «Nie ist der Mann schöner, als wenn er siegreich mit flammender Gesichtsröte, von Pulver und Staub verschmiert, seinen Jubel in die Luft stösst.» (p. 165).

76 «Im Flattern der Fahne spricht der ewige Gott zu den Soldaten [...].» (p.183).
} 
Más publicaciones alemanas sobre la guerra de la Independencia. Las «memorias»...

En su orgullo de guerreros nuestros hombres tenían un aspecto maravilloso [...] jamás un hombre es más bello que en la virilidad indomable del vencedor ${ }^{77}$.

Estos ejemplos de la exaltación de la guerra nos explican, por qué este libro, nada más publicarse, se recomienda en dos reseñas de la época como un texto ejemplar que merece muchos lectores.

Una se titula «Spanien heute und gestern. / Ein badischer Rheinbundoffizier berichtet über seinen Feldzug mit Napoleon» [España hoy y ayer. / Un oficial de Baden en la Confederación del Rin informa sobre su campaña con Napoleón]. Su autor, Christoph v. Imhoff, no pone en duda ni la autoría de v. Holzing ni la autenticidad de los presuntos documentos y menciona a Dufner-Greif como editor. Algunas de las expresiones de Dufner-Greif que nos han llamado la atención y chocado, como arriba indicado, son en el artículo de v. Imhoff objeto de elogio. Además, el autor se refiere a las presuntas crueldades de los franceses y españoles según las describe Dufner-Greif y las contrasta con el siempre ejemplar porte militar de los alemanes, lo que, según dice, demuestra el excelente estudio del carácter de los tres pueblos en dichas memorias. El libro le sirve también para comparar e interpretar la España durante la guerra de la Independencia con la de su tiempo: «Sin quererlo, un soldado que había conocido España [...] hace más de cien años nos demuestra aquí que la falsa doctrina del bolchevismo tiene que haber encontrado en España un suelo abonado» ${ }^{78}$.

La segunda reseña es de Karl Willy Straub. Se publicó en la revista Die Wacht im Westen, 1936/1937. Straub habla claramente de una novela histórica y elogia el texto como un documento ejemplar del excelente porte militar alemán y un libro lleno de sabiduría, «un poema heroico», que «no debe de faltar en ningún instituto pedagógico de la juventud alemana» 79 .

Después de haber demostrado que Dufner-Greif escribió una novela sobre la guerra de la Independencia española, queremos dejarle hablar a él mismo. En un corto texto autobiográfico, publicado en 1935, escribe: «El amor al estado militar de Prusia me llevó al estudio de la historia militar. Sobre todo me entusiasmé por las épocas de Federico el Grande y de las guerras de la independencia. Una gran novela histórica, que se basa en el minucioso estudio archivístico y el conocimiento

77 «Unsere Kerle sahen in ihrem Kriegerstolz hinreissend aus [...] nie ist ein Mann schöner als in der wilden Männlichkeit des Siegers.» (p. 191).

78 «Ein soldat, der Spanien [...] vor mehr als hundert Jahren erlebte, beweist uns hier ungewollt, dass die Irrlehre des Bolschewismus in Spanien einen günstigen Nährboden finden musste.» Imhoff, [Christoph] v.: «Spanien heute und gestern. / Ein badischer Rheinbundoffizier berichtet über seinen Feldzug mit Napoleon.» En: Adelsblatt, 1936, pp. 1749 y 1750. Cita: p. 1750. Damos las gracias a Antonia Braun del Institut für Deutsche Adelsforschung de Kiel por habernos enviado estas dos hojas.

79 «[...] Heldengedicht, das in keiner Erziehungsanstalt deutscher Jugend fehlen sollte.» Straub, Karl Willy: «Max Dufner=Greif, ein deutscher Dichter am Oberrhein.» En: Die Wacht im Westen, 4 $(36 / 37)$. No podemos poner los números de páginas, porque en las copias recibidas no aparecen. 
de la literatura, trata de los heroicos combates de las tropas de Baden en España. El libro está escrito en la forma de las memorias inventadas y dedicado a Karl Franz von Holzing, un cabo de Baden. Quizás un editor que no sea de Baden tenga el valor de publicar esta obra» ${ }^{80}$. Pronto se cumplió este deseo y se publicó su novela histórica bajo el nombre del protagonista Karl Franz v. Holzing ${ }^{81}$. Resumiendo podemos decir que Dufner-Greif utilizó a v. Holzing para sus propios fines: la idealización del soldado alemán, sobre todo de las tropas de Baden, y la glorificación de la guerra.

\section{ANEXO 1}

\section{Las tropas de Baden en la guerra de la Independencia ${ }^{82}$}

23.07.1808 Napoleón exige al Gran Duque Carl Friedrich de Baden un regimiento de infantería y una batería de artillería.

24.08.1808 Un regimiento de infantería y una batería a pie de Baden cruzan el Rin cerca de Kehl.

24.08. - 12.10. 1808 Las tropas de Baden pasan por Francia, a través de Estrasburgo, Metz y Orleáns hasta Bayona - unos mil kilómetros en 48 días.

13.10.1808 Llegada a Irún.

15. - 24.10.1808 En Durango se forma la llamada Deutsche Division bajo el mando del general francés Leval. Consta de tres brigadas:

1. Brigada del coronel von Porbeck de Baden:

Regimiento de infantería de Baden, $\mathrm{n} . \stackrel{0}{4}$,

Regimiento de infantería de Nassau, $n . \stackrel{\circ}{2}$,

Batería a pie de Baden.

80 Véase: nota 26: Dufner-Greif (1935), op. cit., p. 81; versión alemana: «Die Liebe zum preussischen Soldatentum führte mich zum Studium der Kriegsgeschichte. Den Zeitaltern Friedrichs des Grossen und der Freiheitskriege gehört darin meine leidenschaftliche Vorliebe. Ein grosser Geschichtsroman, sachlich auf genauer Archivforschung und Literaturkenntnis fussend, behandelt die heldenmütigen Kämpfe der badischen Truppen in Spanien. Das Buch ist in der Form erdachter Denkwürdigkeiten geschrieben und dem Andenken des badischen Hauptmanns Karl Franz von Holzing gewidmet. Vielleicht hat ein ausserbadischer Verleger einmal den Mut zur Drucklegung dieses Werkes. «

${ }^{81}$ En el libro no aparece el año de publicación, pero se indica 1937 como año del copyright, y este año se cita en la literatura consultada. No obstante, podría haberse publicado ya un año antes, porque una de las dos reseñas arriba mencionadas data de 1936 y en la otra se indica con lápiz: 4 (36/37).

82 Texto abreviado y traducido de: Blankenhorn, Erich: 1808-1814. Badische Truppen in Spanien. Amtliche Veröffentlichung des Armeemuseums Karsruhe / Baden Deutsche Wehr am Oberrhein. Karlsruhe (Braun) 1939, pp. 6-13.

Una de las fuentes de Blankenhorn es: Sauzey, [Jean-Camille-Abel-Fleuri]: Les Allemands sous les Aigles Françaises. Essai sur les Troupes de la Confédération du Rhin 1806-1814. 5 tomos. París 19021912. Tomo 2: Le Contingent Badois. Avec un Préface de M.J. Margerand. París 1904. Los tomos 1, 2 y 3 de esta obra se encuentran en la Biblioteca del Senado, Madrid. Entre las fuentes alemanas de Sauzey figura la obra de Franz Xaver Rigel. 
2. Brigada del general holandés Chassé:

Regimiento de infantería de Holanda,

Regimiento de húsares de Holanda,

Batería a caballo de Holanda.

3. Brigada del general francés Grandjeau:

Batallón de la guardia de París,

Batallón de Frankfurt,

Regimiento de infantería de Hessen,

Media batería a pie de Hessen.

Octubre/noviembre 1808 Napoleón está desde el 2 de noviembre en Vitoria. Sus 200.000 soldados pasan el Ebro y se dirigen al centro de España. La Deutsche Division lucha en su ala oeste : Zornoza: 24.10., Durango 31.10., Valmaseda 8.11.

08. y 09.11.1808 La Deutsche Division se reúne antes de entrar en Madrid. También las tropas de Baden que habían luchado en diferentes lugares.

10.12.1808 Napoleón pasa revista y la Deutsche Division se acantona.

Una de sus obligaciones es el servicio de guardia del rey José.

15.12.1808-13.01.1809 La artillería de la Deutsche Division (Baden, Hessen y Holanda), formando parte de un cuerpo francés, participa en un forzoso reconocimiento del Tajo.

13.01.1809 Madrid está amenazada desde el Sur. Napoleón manda el cierre de los puentes del Tajo. Junto con otras tropas la Deutsche Division sale de la capital. El regimiento de Baden ya sólo cuenta con novecientos hombres, setecientos están en hospitales de campaña y doscientos ya han muerto. A la Deutsche Division se acoplan los batallones ajenos de Prusia, Westfalia e Irlanda.

17.01.1809 Desde Valladolid Napoleón deja España para siempre. A partir de entonces falta el mando central de las tropas francesas dispersas por la península.

Durante las primeras semanas de 1809 las acciones de la Deutsche Division se limitan a pequeños encuentros en los puentes del Tajo de Talavera a Almaraz.

Durante el mes de marzo tropas alemanas de Nassau y Baden luchan en las montañas al otro lado del Tajo (17.03. Mesa de Ibor, 18.03. Val de Cañas), abriendo camino al mariscal Victor y su ejército.

28.03.1809 Batalla de Medellín entre las tropas del general Cuesta y del mariscal Victor. Derrota de los españoles. Baden no tiene bajas, sólo algunos heridos.

Abril/mayo $1809 \mathrm{El}$ general Wellesley sorprende a los franceses cerca de Oporto y los expulsa de Portugal. El mariscal Victor se retira con su ejército al otro lado del Tajo.

El 23.05 La Deutsche Division atraviesa el puente de barcas cerca de Almaraz. Se les destina a las montañas del Tiétar y son obligados a vengarse de las crueldades de la población.

27. y 28.07.1809 Batalla de Talavera. Bajo el mando del general Wellesley (después de esta batalla nombrado Duque de Wellington) combaten 20.000 ingleses, alemanes (Deutsche Legion [The King's German Legion], 3336 hombres) y portugueses y 32.000 españoles contra 46.000 franceses y sus aliados, entre ellos la Deutsche Division, que está en primera línea con 4267 hombres. Lucharon alemanes contra alemanes y sus bajas fueron conjuntamente de unos 2.000 hombres, entre ellos en el lado inglés el general de brigada Ernst Eber- 
hard Kuno Langwerth von Simmern (1757-1809) y en el lado francés el general Heinrich von Porbeck (1771-1809) de Baden. La batalla terminó sin un resultado claro.

29.07.1809 Napoleón cambia el nombre de la Deutsche Division por el de Rheinische Bundesdivision [División de la Confederación del Rin].

Agosto a noviembre 1809 Batallas de Almonacid y de Ocaña, ganadas por los franceses.

Noviembre/diciembre 1809 La Rheinische Bundesdivision es encargada de llevar a los presos (3 generales, 700 oficiales, 15.000 soldados) desde Madrid a Bayona. Las tropas de Baden regresan el 26.12.1809 a España, junto con su nuevo comandante, el general von Neuenstein (1767-1838).

Enero a marzo 1810 La Rheinische Bundesdivision es encargada de asegurar los caminos de Madrid a Francia y de escoltar los correos y transportes, una tarea complicada que genera muchas bajas.

1810/1811 El 26.03.1810 Se envía a una parte de la Rheinische Bundesdivision (Baden, Nassau, Frankfurt) como tropa de ocupación a La Mancha, su destino por casi dos años. En 1811 son en total 5.527 soldados, 1.181 de ellos se encuentran en hospitales. Su comandante, el general Carl von Neuenstein (1767-1839), reside en Consuegra. Los alemanes se desgastan en la lucha con las guerrillas.

Diciembre 1811 a enero 1812 Un batallón de Baden acompaña a los franceses a la provincia de Valencia.

1812 Año decisivo para España. Napoleón retira 60.000 de sus mejores tropas de España para enviarlas a Rusia. Se sustituyen por 35.000 reclutas. Todavía hay unos 230.000 mil franceses en España, frente a un ejército luso-británico de 55.000 hombres y un ejército español formándose. Además hay unos 50.000 soldados españoles entre las guerrillas.

Wellington gana la batalla de Salamanca y el 12 de agosto entra en Madrid.

1813. El 18.03. el rey José abandona definitivamente Madrid. Pierde la batalla de Vitoria y huye a través de los Pirineos a Francia. En su retaguardia están los alemanes, que también han sufrido grandes pérdidas. El 6.07.1813 atraviesan la frontera junto con las últimas tropas francesas.

Napoleón nombra al mariscal Soult comandante general de su ejército en la península, al cual pertenecen también tropas de Baden, Nassau y Frankfurt, pero fracasa con sus intentos de ganar de nuevo terreno español. El 10.12.1813 el regimiento Nassau y el batallón Frankfurt se pasan al enemigo inglés. Al día siguiente los franceses desarman a las tropas de Baden y las llevan al cautiverio, los oficiales a Normandía y los soldados a Borgoña, desde donde regresan el 14.05.1814. 
ANEXO 2

\section{Relación bibliográfica}

\section{Anónimos}

Badischer Militär-Almanach. 10 tomos. Karlsruhe (G. Braun) 1854-63.

Briefe aus Spanien von einem deutschen Militär. s.I. 1810.

Das Badener Land. 1903.

Die Männer der Nacht, oder wundervolle Abentheuer eines Offiziers während seiner Feldzüge in Spanien. s.l. 1811.

Feldpostbrief eines einfachen Mainzer Infanteristen aus Napoleons Krieg in Spanien. Versión PDF en internet.

Feldzug von Portugal in den Jahren 1811 und 1812 in historischer und medizinischer Hinsicht, beschrieben von einem Arzte der französischen Armee von Portugal. Stuttgart 1816. 2. ${ }^{\text {a }}$ ed.: Tübingen (Cotta) 1817.

Feldzüge des Jahres 1809. Berlín (Schütz \& Schulz) 1837.

Lesebuch für Unteroffiziere und Soldaten des Grossherzogl. Badischen Armeekorps. Karlsruhe (C.F. Müller) 1824.

Napoleon in Spanien im Jahre 1808. Militärisches Drama in 4 Akten. Viena (M. Lell) 1856.

Unter dem Greifen, altbadisches Militär von der Vereinigung der Markgrafschaften bis zur Reichsgründung 1771-1871. Ed: Vereinigung der Freunde des Wehrpolitischen Museums Schloss Rastatt e.V. Karlsruhe 1984.

\section{Autores por orden alfabético}

ARNDT, Ernst Moritz: Kurze und wahrhaftige Erzählung von Napoleon Bonapartens verderblichen Anschlägen, von seinen Kriegen in Spanien und Russland, von der Zerstörung seiner Heeresmacht, und von der Bedeutung des gegenwärtigen teutschen Krieges: ein Büchlein dem teutschen Volke zum Trost und zur Ermahnung gestellt. Leipzig (Fleischer) 1814.

ARNDT, Ernst Mortiz: Zwei Worte über die Entstehung und Bestimmung der Teutschen Legion. Dresde 1813. 2. ㄹ ed. Königsberg 1814.

Baumgarten, Hermann: Geschichte Spaniens vom Ausbruch der französischen Revolution bis auf unsere Tage. 3 vols. Leipzig (S. Herzel) 1865.

BеСнт: Denkwürdigkeiten der zwey Feldzüge Grossherzogl. Bad. Truppen im Elsasse in den Jahren 1814 und 15 nebst einer gedrängten unparteiischen Darstellung der Geschichte des Grossh. Bad. Linien-Inf.-Regts. von Neuenstein seit seiner Errichtung bis zu seinem Rückmarsch aus Spanien ins Vaterland. Heidelberg (Selbstverlag) 1817. 
BeEthoven, Ludwig van: Wellingtons Sieg oder die Schlacht bei Vittoria. Op. 91. Sinfonisches Orchesterwerk. 1813. Internet: http://de.wikipedia.org/wiki/Wellingtons_Sieg

BLANKENHORN, Erich: 1808-1814, Badische Truppen in Spanien. Amtliche Veröffentlichung des Armeemuseums Karlsruhe-Baden, Deutsche Wehr am Oberrhein. Karlsruhe (Braun) 1939.

BleibTREu, Karl y Detlef WenZlik: Marschälle, Generale, Soldaten Napoleons I. S. I. (VRZ) 1994.

Cramer, Carl Gottlob (Ed.): Rückerinnerungen aus Spanien. Mit dem Bildnisse des Friedensfürsten. Aarau 1810.

Bratring, Friedrich Wilhelm August: Spanien und die Spanier. = Tomo 2 de: Welt- und Menschenkunde. Berlín (Rücker) 1811.

FIEDLER, Siegfried: «Das Militärwesen Badens in der Zeit Napoleons.» En: Baden und Württemberg im Zeitalter Napoleons. Ausstellung des Landes Baden-Württemberg. Ed.: Württembergisches Landesmuseum Stuttgart. 2 tomos. Stuttgart 1987. Tomo 2.

Fromm, F. L.: Nachrichten über die heldenmüthige Verteidigung von Saragossa durch die Spanier, in den Jahren 1808 und 1809. Gesammelt und hrsg. von einem königlich preussischen Ingenieur-Officier. Berlín 1816.

GEIGER: Geschichte des Linien-Infanterie-Regiments Erbgrossherzog Nr. 2. Manuscrito. Armeemuseum Karlsruhe.

GoETHE, Johann Wolfgang von: Prólogo a: Memoiren Robert Guillemard's verabschiedeten Sergenten: begleitet mit historischen meisten theils ungedruckten Belegen von 1805 bis 1823. Leipzig (Weygand) 1827. [Traductor: Johann Christian Mämpel, autor de la obra Der junge Feldjäger...].

HAFFnER, J. D.: Geschichtliche Darstellung des Grossherzoglich Badischen Armeekorps. Karlsruhe (Malsch \& Vogel) 1840.

HeInE, Leberecht: Die Abentheuer in dem Spanischen Feldzuge 1809 bis 1814. Dessau 1835. Manuscrito. Stadtarchiv Zerbst. [Algunos fragmentos publicados en: Zeidler, Ludwig: Der spanische Feldzug des Bataillons Anhalt im J. 1810. Zerbst (Römer) 1844].

HeLmes, Hermann: Die Würzburger Truppen vor hundert Jahren. Archiv des historischen Vereins von Unterfranken und Aschaffenburg. Tomo 55. s.I., s.a.

Holleben, Wilhelm von: Geschichte der Familie von Holleben. Gotha 1895.

HOYER, Johann Gottfried von: Die Franzosen in Spanien: Ein historischer Versuch nach den besten gleichzeitigen Quellen. Dresde (Arnold) 1809.

HUFNER, Martin: «1813. Dr. Hufner analysiert: Beethoven, Wellingtons Sieg oder Die Schlacht bei Vittoria op. 91.» En: Enzyklopädie der kritischen Masse. Internet. http:www.kritischemasse.de/blog/content/1813-dr-hufner-anaylsiert-de

Hundert, Karl: Die Fahne des Bataillons Anhalt in Spanien. Zerbst 1910.

KIRCHEISEN, Friedrich: Napoleon I. Sein Leben und seine Zeit. 9 tomos. Munich (Georg Hirth) 1929-1934.

KITTLITZ, Freiherr von: Kriegs- und Friedensarbeit des Anhaltischen Infanterie Regiments 1807-1907. Dessau 1913. 
Más publicaciones alemanas sobre la guerra de la Independencia. Las «memorias»...

KNÖTEL, R.: Handbuch der Uniformkunde. Leipzig (Weber) 1896.

$\mathrm{KocH}$, Herbert: «El diario de Juan Jacobo David Otto, militar en España en el año 1810». En: Boletín de la Real Academia de la Historia (Madrid), CLII, núm. 1 (1961), pp. 111-115.

KrausleR, Franz Georg Friedrich und J. E. Woerl: Die Kriege von 1792 bis 1815 in Europa und Ägypten mit besonderer Rücksicht auf die Schlachten Napoleons und seiner Zeit. 2 tomos. Karlsruhe, Freiburg (Herder) 1840. [Tomo 1: texto; tomo 2: 135 mapas y planos. 2. ${ }^{\text {a }}$ ed. 1842 texto, mapas y planos en 1 tomo; 3. ${ }^{a}$ ed. en 2 tomos].

KüSTER: Geschichte des Anhaltischen Infanterie-Regiments Nr. 93. 2 vols. Berlín (Mittler) 1893-95. [Con ilustraciones].

LOHMANN, W.: «Kriegstagebuch eines anhaltischen Handwerkers über die Feldzüge in Tirol und Spanien. En: Ascania, n. 41. 2 de octubre de 1908.

MerKLE, Hans: «Vor zweihundert Jahren: Badische Soldaten in Spanien (1808-1814)». En: Badische Heimat. 88, Cuaderno 2, junio 2008, pp. 263-279.

MeYeR, Karl J.: Napoleons Soldaten. Alltag in der Grande Armee. Darmstadt (Primus) 2008. (= Geschichte erzählt, tomo 12).

MuHL, Georg: Denkwürdigkeiten aus dem Leben des Freiherrn von Schäffer. Pforzheim (Dennig, Fink \& Co.) 1840.

Niemann, Hans: «Das Heereswesen in Anhalt.» En: Anhaltischer Anzeiger. 21 de mayo de 1938.

OfFEN, Karin: Verlustliste. Verluste der Königlich Deutschen Legion (hauptsächlich Offiziere) 1803- 1815. Internet: Genealogische Gesellschaft Hamburg ev.

OMPteda, Christian v.: In the King's German Legion. Cambridge (Ken Trotman Ltd.) 1987. [Traducción de la edición alemana de las memorias del Baron Ompteda. Ed.: su sobrino, Louis v. Ompteda].

PAULING, Günther: Der Höllenmarsch durch Katalonien. Halle (Projekte-Verlag) 2009. [Novela histórica. Con fotos de Cabrera].

POHLER, Johann von: Bibliotheca historico-militaris: systematische Übersicht der Erscheinungen aller Sprachen auf dem Gebiete der Geschichte der Kriege und Kriegswissenschaft seit der Erfindung der Buchdruckerkunst bis zum Schluss des Jahres 1880. Kassel 1890. Tomo II, pp. 49 y sigs.

RADERS, Margit: «España durante la Guerra de la Independencia en la mirada de combatientes y viajeros alemanes.» En: Raposo, Berta y Eckhard Weber (Eds.): Guerra y viaje. Una constante histórico-literaria entre España y Alemania. Valencia (Universidad de Valencia) 2009, pp. 113-127.

RIGEL, Franz Xaver: Blockade, Belagerung und Eroberung von Tortosa. Mannheim (Götz) 1847.

RINK, Martin: «Die Erfindung des Guerillakrieges. Der Dos de Mayo 1808 - Auftakt zum Spanischen Unabhängigkeitskrieg». En: Militärgeschichtliche Zeitschrift für historische Bildung. 1/2008, pp. 4-9. También en internet. http://www.mgfa.de/ZMG_1_2008

RüCKERT, L.: Erlebnisse im spanischen Feldzug 1809-13. Diario, manuscrito. Generallandesarchiv Karlsruhe. [Versión abreviada y cambiada, escrita en tercera persona, en: Weech, 
Friedrich v.: «Badische Truppen in Spanien 1810-1813 nach den Aufzeichnungen eines badischen Offiziers.» En: Badische Neujahrsblätter. 2, Karlsruhe (G. Braun) 1892].

Ruppent, Andreas: «Francisquete». En: Tranvía, n. 33, Berlín, junio de 1994, pp. $42-44$.

SCHMIDT, Ernst-Heinrich: «Troops from Baden fighting in the Confederation of the Rhine Forces in the Peninsula War, 1808-1809.» En: MILITARIA. Revista de Cultura Militar, n.․․

7. Servicio de Publicaciones, UCM Madrid, 1995, pp. 359-389.

SCHULZE, Ernst (Ed.): Scenen auf dem Kriegsschauplatze von Spanien. s.I. s.a.

SCHULZE, Ernst (Ed.): Memoiren über den Krieg der Franzosen in Spanien. s.l. s.a. [¿1908?].

SCHULZE, Robert: Die Teilnahme anhaltischer Krieger an den Feldzügen für und gegen Napoleón 1807 bis 1815. Köthen 1921.

SEEBACH, Ludwig von: Geschichte der Feldzüge des herzoglich Sachsen-Weimarischen Scharfschützenbataillons im Jahr 1806 und des Infanterie-Regiments der Herzöge von Sachsen in den Jahren 1807, 1809, 1810 und 1811. Weimar (Voigt) 1838. [Con ilustraciones y 4 planos].

SOMmeRLATt, Christian Vollrath v.: Züge teutschen Muthes und Hochsinnes. 2 tomos. Basilea (Schweighäuser) 1820. [Con grabados]. 2. a ed. 1825, 3. a ed. 1826.

STEHLE, Ludwig: Berger Ortschronik. Espira 1980. [Con un capítulo sobre el general FranzXaver von Schwarz, pp. 40-43].

STRICKER, Wilhelm: Germania: Archiv zur Kenntnis des deutschen Elements in allen Ländern der Erde. Frankfurt am Main (Broenner) 1850.

TRÖGE, Walter: Thüringer Landeskinder unter Napoleons Fahnen in Spanien (1810). Neustadt / Orla (Wagner) 1937.

UMHEY, Alfred: Badische Truppen in Spanien - eine ikonographische Betrachtung. [s.l. s.a.]

VENTURINI, Karl Heinrich Georg: Geschichte unserer Zeit. 1809. Leipzig 1811.

VögELY, Ludwig: «Unter Napoleon in Spanien. Denkwürdigkeiten des Hauptmanns Karl Franz von Holzing (1787-1839).» En: Badische Heimat. 69, cuaderno 1, marzo 1989, pp. 211-218.

VÖGELY, Ludwig: «Die Erlebnisse Karl Franz von Holzings in spanischer Gefangenschaft.» En: «So weit der Turmberg grüsst». Beiträge zur Kulturgeschichte, Heimatgeschichte und Volkskunde. 9, n. , febrero 1957, pp. 16-19.

WalleR, Anneliese: Baden und Frankreich in der Rheinbundzeit 1805/13. Tesis doctoral. Freiburg 1935.

WEECH, Friedrich v.: Badische Biographien. Tomos 1 y 2. Heidelberg (Bassermann) 1875.

WenZLIK, Detlef: Die Schlacht von La Coruña. 16. Januar 1809. s.I. (VRZ) 2004.

WENZLIK, Detlef: Die Schlacht von Albuera. 16. Mai 1811. s.I. (VRZ) 2004.

WENZLIK, Detlef: Die Schlachten bei Oporto und Talavera. 1809. s.I. (VRZ) 2004.

ZeHFuss, Heinrich: Geschichte des im Jahre 1852 zu Darmstadt errichteten Denkmals für die in der Periode von 1792 bis 1815 auf dem Felde der Ehre gefallenen Grossherzoglich Hessischen Krieger. Darmstadt 1853. 
Más publicaciones alemanas sobre la guerra de la Independencia. Las «memorias»...

ZeIDLER, Rosa (Ed.): Der spanische Feldzug des Bataillons Anhalt im Jahre 1810. Dargestellt von Ludwig Zeidler, weiland Collaborator am Francisceum zu Zerbst. Zerbst (H. Zeidler) 1927. [Edición algo abreviada de la obra de Ludwig Zeidler de 1844]. 
